\title{
Are some of the stigmas of addictions culturally sanctioned?
}

Patrick Corrigan, Georg Schomerus and David Smelson

\section{Summary}

We provide three examples of how addiction stigma is sanctioned: (a) discrimination against people with addictions is often legal; (b) public health communications frequently use stigma to promote prevention; (c) some programmes, such as '12 steps' promote self-stigma. The implications of sanctioned stigma for stigma-change programmes are then discussed.

\section{Declaration of interest}

None.

\section{Copyright and usage}

(c) The Royal College of Psychiatrists 2017.
Patrick Corrigan (pictured) is a Distinguished Professor of Psychology at the Illinois Institute of Technology in Chicago. Georg schomerus is a Professor in the Department of Psychiatry at Greifswald University. David Smelson is a Professor of Psychiatry at the University of Massachusetts Medical School in Worcester.

Advocates and other stakeholders agree that the recovery of people challenged by behavioural health conditions is undermined by stigma. Stigma is the discrimination that results when the public endorses stereotypes about a group. ${ }^{1}$ As a result, people with behavioural health conditions, for example, are not able to achieve life goals related to employment, health, relationships and housing. Thus, leaders of the World Health Organization $(\mathrm{WHO})^{2}$ as well as the Substance Abuse and Mental Health Administration (SAMHSA) in the USA, have called for research to better understand the nature of these problems and ways to counteract them. SAMHSA engaged the US National Academy of Science (NAS) in 2014 to summarise the state of research on the stigma of behavioural health: mental illness and addictions. In P.C.'s work on that panel, and in earlier comparative studies by Schomerus et $a l^{3}$, we identified a fundamental difference between the stigma of those with mental illnesses $v$. those with addictions. Whereas the stigma of mental illness is mostly recognised as a social injustice worthy of coordinated advocacy meant to erase it, the stigma of addiction is in some ways socially, politically, and/or legally sanctioned in most places around the world and, as such, included in active efforts to control substance possession and use. As a result, what seems to be an easy mantra of the stigma movement for mental health - erase its effects to promote recovery - is muddied for addiction. Three examples of sanctioned stigma are reviewed in this paper in order to illustrate problematic uses of addiction stigma. We then consider these examples in light of their implications for the broader agenda of addressing the stigma of addictions.

\section{Discrimination against people with addictions is legal}

Although the justice system is often concerned about the role of mental illness in criminal guilt and fitness to stand trial, it mostly protects the civil rights of people with serious mental illness. ${ }^{4}$ Much less so for people with substance use disorders. Use of controlled substances including cocaine, opioids and some medications such as amphetamines and barbiturates is illegal in most geopolitical jurisdictions. Penalties for illicit use can vary from a monetary fine to an extended prison term. Socially benign substances such as alcohol and tobacco are often legally controlled; for example, people under age 18 to 21 (depending on jurisdiction) are not permitted to purchase or use these substances. Supervisors can reprimand employees found to be under the influence of alcohol or other psychoactive substances at work.

Addiction stigma is likely worsened by criminalisation, by conflating drug use with felonious behaviour. In the Western world, pairing criminal behaviour with addiction got a significant boost with the launch of the 1970s war on drugs by the Nixon administration. The war's effects were significant in the USA; one in every 136 adults was incarcerated for drug possession in $2005 .{ }^{5}$ Although public sentiment about criminalising people for drug possession and use has waned (for example, the US Department of Justice has been prompting criminal deinstitutionalisation and alternatives to incarceration through the 'Second Chance Act'), research shows that people who agree with criminal penalties for drug use still endorse the stigma of people labelled with substance use disorder. ${ }^{6}$

Addiction stigma also has an impact on interpretation of civil law. Consider, for example, reasonable adjustment requirements of the Equality Act in the UK or the Americans with Disabilities Act (ADA). Reasonable accommodations are guaranteed under the law to help people with disabilities - people who use wheelchairs, for example, or those with serious mental illness - successfully complete work-related duties so they can accomplish vocational goals. ADA protections for addictions are comparatively limited. Individuals with addictions do qualify for ADA protections if successfully treated and if they are no longer engaged in the illegal use of drugs or are currently engaged in a treatment programme and not using illegal drugs. Relapse leads to trouble, however. Employers are not violating these acts when disciplining employees - including discharge or denying promotions - currently engaged in illegal use of drugs. The Equality Act and reasonable adjustments continue to support people with mental illness who experience recurring symptoms.

\section{Stigma is used to promote prevention}

Stigmatising may be unintentionally incorporated into health communication strategies to promote substance use prevention in two ways. ${ }^{7}$

(a) Stressing the criminal-addiction connection. For example, health campaigns have paired drug use with illegal or unethical activity. The United Nations established the Office for Drug Control and Crime Prevention (ODCCP) to 
address this goal. Mothers Against Drunk Driving builds much of its public awareness campaign by pairing alcohol and drug use with horrific scenes of car accidents and death. The 2002 Super Bowl football game in the USA compared drug use to terrorism by connecting illegal drug buyers to the extremists who operate the narco-market beneath it.

(b) Public service announcements seek to promote prevention by tying drug use to poor health, ${ }^{8}$ an especially popular approach for youth programmes. The United Nations ODCCP released a $30 \mathrm{~s}$ public service announcement in 2010 that followed four young people whose health deteriorates as they use drugs. The 2014 Worlds AIDS campaign targeted 15- to 24-year-olds by tying drug use to contracting HIV.

\section{Some interventions worsen self-stigma}

'Twelve step' and some other programmes address substance use disorders by encouraging members to recognise their absence of power vis-à-vis addictions, admit character defects that result from this powerlessness and make amends to those they have wronged. This approach partly corresponds with disease models that frame people as unable to control substance use because of biological predispositions and may unintentionally promote selfstigma. In mental illness research, self-stigma is often found as an unintended effect of disease models, often diminishing feelings of self-worth among people. Recovery models have offset these effects with two perspectives: outcome and process. ${ }^{9}$ Outcome models describe recovery as a state where symptoms are remitted, disabilities overcome and goals achieved. Process models view recovery as a journey described by hope where people pursue personally defined goals regardless of symptoms and disabilities. Recovery reintroduced hope and optimism into discussion of serious mental illnesses, in the process becoming a fundamental tool in tearing down the stigma of mental illness.

Definitions of recovery from addictions are much more complex, with providers and advocates not always agreeing on the best definitions. ${ }^{10}$ Recovery is viewed on a continuum for mental illness, whereas it is often represented as having only a single value - abstinence - in disease models of addiction. Beliefs about achieving goals may vary depending on whether someone assumes abstinence must be accomplished first. Although recovery from mental illness is grounded in hope, recovery from addiction sometimes begins with hopelessness and hitting rock bottom for many programmes adopting a disease model. Recovery from addictions, according to this perspective, may only occur when people recognise their powerlessness in the face of substances.

This sense of powerlessness suggests different perspectives on self-determination between mental health and addictions communities. Fundamental to mental health are systems that empower people to define life goals for themselves and then select interventions that help them achieve those goals. Selfdetermination may be tempered by 12 step and other addiction programmes with concerns about impulsivity where people are warned not to be fooled by aspirations given past failures from substance use.

\section{Erasing the stigma}

The social injustice of stigma rallies progressives to erase it in all its forms. And although the end is difficult to achieve and decades in the making, the goal is easy to understand. Stop it. Stop the stereotypes, prejudices and discrimination against people with mental illness. Rarely are mental health and policy advocates derailed by misunderstanding the goal. However, this is not the case for addictions. Because some stigmas are legally or socially sanctioned, changing them is a much more complex task. With addictions, stopping stigma is not so easy, even with the harm reduction paradigm shift, which moves us closer to promoting client choice. Nor are there easy changes to right the ship of anti-stigma efforts for addictions. Criminalising addiction might be stigmatising, but no easy consensus will be found in decreasing stigma by breaking the connection between substance use disorders and crime. Using stigma in health communication strategies might seem contrary to public health intentions, but we doubt activists will agree this tool should be eliminated. Unlike mental health, the stigma of addiction does not target an irrefutable goal for advocates attempting to stem stigma's harmful effects.

Seemingly, the inherent purpose of addiction stigma is to reduce substance use. Many might consider it acceptable to endorse stigma should this purpose be achieved. But we have to ask: is it really acceptable to use stigma as a public health tool? And does stigma in fact reduce substance use, or does it, as mounting evidence suggests, do more harm than good? And further: how can substance use problems be better managed without stigma, without devaluation, discrimination and exclusion of people with addictions? As advocates of social change, these are exquisitely complex questions that advocates, providers and people with lived experience need to consider with the benefit of empirical research.

Patrick Corrigan, PSyD, Illinois Institute of Technology, Chicago, Illinois, USA; Georg Schomerus, MD, PhD, Department of Psychiatry, Greifswald University, Greifswald, Germany; David Smelson, PsyD, University of Massachusetts Medical school, Worcester, Massachusetts, USA

Correspondence: Patrick Corrigan, 3424 S State Street, Illinois Institute of Technology, Chicago, Illinois, USA; Email: corrigan@iit.edu

First received 22 Mar 2016, final revision 8 Jul 2016, accepted 6 Sep 2016

\section{References}

1 Lloyd, C. The stigmatization of problem drug users: a narrative literature review. Drugs Educ Prev Pol 2013; 20: 85-95.

2 Keiny M. UNGASS 2016 on the World Drug Problem: Focus on People, Public Health and Human Rights. WHO, 2015 (http://www.who.int/medicines/news/ ungass2016-world-drug-problems/en/).

3 Schomerus G, Lucht M, Holzinger A, Matschinger H, Carta MG, Angermeyer MC. The stigma of alcohol dependence compared with other mental disorders: a review of population studies. Alcohol Alcohol 2011; 46: 105-12.

4 Callard F, Arboleda-Flórez J. Mental Illness, Discrimination and the Law: Fighting for Social Justice. John Wiley \& Sons, 2012.

5 Peterson, K. National Reforms Needed to Help Inmates Return Home. The PEW Charitable Trusts, 2005 (http://www.pewtrusts.org/en/researchand-analysis/blogs/stateline/2005/01/14/national-reforms-needed-to-helpinmates-return-home).

6 West ML, Yanos PT, Mulay AL. Triple stigma of forensic psychiatric patients: mental illness, race, and criminal history. Int J Forensic Ment Health 2014; 13: $75-90$.

7 Schomerus G. The stigma of alcohol and other substance abuse. In The Stigma of Disease and Disability: Understanding Causes and Overcoming Injustices (ed P Corrigan): 57-72. American Psychological Association, 2014.

8 Gutman N, Salmon CT. Guilt, fear, stigma and knowledge gaps: ethical issues in public health communication interventions. Bioethics 2004; 18: 531-52.

9 Ralph RO, Corrigan PW. Recovery in Mental IIIness: Broadening our Understanding of Wellness. American Psychological Association, 2005.

10 White WL. Nonclinical addiction recovery support services: history, rationale, models, potentials, and pitfalls. Alcohol Treat Q 2010; 28: 256-72. 